\title{
Genetic Variability and the Potential Range of Darevskia rostombekowi in Transcaucasia
}

\author{
F. A. Osipov ${ }^{a, ~ *}$, A. A. Vergun ${ }^{b, c}$, M. S. Arakelyan ${ }^{d}$, R. K. Petrosyan ${ }^{d}$, N. N. Dergunova ${ }^{a}$, \\ L. A. Neymark ${ }^{a}$, and V. G. Petrosyan ${ }^{a}$ \\ ${ }^{a}$ Severtsov Institute of Ecology and Evolution, Russian Academy of Sciences, Moscow, 119071 Russia \\ ${ }^{b}$ Institute of Gene Biology, Russian Academy of Sciences, Moscow, 119334 Russia \\ ${ }^{c}$ Moscow Pedagogical State University, Moscow, 119991 Russia \\ ${ }^{d}$ Department of Biology, Yerevan State University, Yerevan, 0025 Armenia \\ *e-mail: osipov_feodor@mail.ru
}

Received August 26, 2019; revised November 11, 2019; accepted November 11, 2019

\begin{abstract}
The results of the analysis of the genetic variability of parthenogenetic Darevskia rostombekowi (Darevsky, 1957) species using four microsatellite-containing loci are presented. Based on 118 records with geographical coordinates of the presence of this species in Transcaucasia, the maps of potential range were created. The analysis of the genetic structure of populations demonstrated that despite the established multiclonality (seven clonal lines in four populations), D. rostombekowi was formed as a result of a single act of hybridization between closely related bisexual species. The predicted distribution of $D$. rostombekowi using the modelling of potential range revealed new suitable habitats, where the presence of the species has not been reported previously. The results of this study and the absence of multiple acts of hybridization during the formation of these clones may indicate a regression of population size of the species. Consequently, the estimation of the conservation status of this parthenogenetic species seems to be justified.
\end{abstract}

DOI: $10.1134 / \mathrm{S} 1062359021050101$

\section{INTRODUCTION}

Over the past 50 years, the results of cytogenetic, molecular genetic analyses of unisexual and bisexual complexes of the species of the genus Darevskia were obtained (Darevsky, 1967; Uzzell and Darevsky, 1975; Martirosyan et al., 2002; Malysheva et al., 2002; Malysheva et al., 2006; Osipov et al., 2016; Ryskov et al., 2017). These results indicate the concept of hybridogenic speciation in parthenogenetic species of rock lizards, which consists in the formation of new unisexual hybrid species carrying the genomes inherited from two closely related parental species (Uzzell and Darevsky, 1975; Ryskov et al., 2017). The complex analysis demonstrated that the parthenogenetic D. rostombekowi species was formed as a result of natural hybridization between closely related bisexual species D. portschinskii (paternal species) and D. raddei raddei (maternal species) (Uzzell and Darevsky, 1975). Despite some success in the study of $D$. rostombekowi (MacCulloch et al., 1997; Martirosyan et al., 2002; Osipov et al., 2016; Ryskov et al., 2017), questions about the boundaries of its range and speciesspecific parameters of abiotic environmental factors (determining the area of distribution of isolated populations) remain unclear. The analysis of allozyme loci in individuals of different $D$. rostombekowi populations (except for the isolated Tsovak population) revealed no variability, which presumably indicated a monoclonal genetic structure (MacCulloch et al., 1997).

There are fragmentary data on the distribution of isolated populations of $D$. rostombekowi in Armenia. It is known that the D. rostombekowi lizard (one of seven parthenogeneticspecies of Darevskia rock lizards) occupies a relatively small range consisting of several isolated populations of different sizes within Northern Armenia, adjacent regions of Northwest Azerbaijan, and a small alpine relict ( $\sim 12000$ years) population (detached from the main range) on the southeastern coast of Lake Sevan (MacCulloch et al., 1997; Martirosyan et al., 2002; Arakelyan et al., 2011, Petrosyan et al., 2020a). The boundaries of the range of the species, as well as of isolated populations, are absent in the literature.

The aim of this study was (1) to determine the genetic structure of the populations inhabiting different environmental conditions on the territory of Armenia; (2) to construct a map of the spatial distribution of $D$. rostombekowi based on species occurrence records; and (3) to identify bioclimatic, topographic, and landscape variables that determine the potential range of the species. 
Table 1. List of DNA samples studied

\begin{tabular}{|c|c|c|}
\hline $\begin{array}{l}\text { Population } \\
\text { name }\end{array}$ & $\begin{array}{c}\text { Number } \\
\text { of individuals }\end{array}$ & $\begin{array}{c}\text { Geographical } \\
\text { coordinates }\end{array}$ \\
\hline Gosh & 4 & $\begin{array}{l}40^{\circ} 42^{\prime} 20.3^{\prime \prime} \mathrm{N} \\
45^{\circ} 00^{\prime} 57.7^{\prime \prime} \mathrm{E}\end{array}$ \\
\hline Tsovak & 8 & $\begin{array}{l}40^{\circ} 10^{\prime} 45.0^{\prime \prime} \mathrm{N} \\
45^{\circ} 37^{\prime} 22.7^{\prime \prime} \mathrm{E}\end{array}$ \\
\hline Papanino & 21 & $\begin{array}{l}40^{\circ} 42^{\prime} 27.7^{\prime \prime} \mathrm{N} \\
44^{\circ} 45^{\prime} 43.8^{\prime \prime} \mathrm{E}\end{array}$ \\
\hline Spitak & 9 & $\begin{array}{l}40^{\circ} 48^{\prime} 50.0^{\prime \prime} \mathrm{N} \\
44^{\circ} 16^{\prime} 48.7^{\prime \prime} \mathrm{E}\end{array}$ \\
\hline
\end{tabular}

\section{MATERIALS AND METHODS \\ Molecular Genetic Analysis}

DNA samples of parthenogenetic D. rostombekowi species $(n=42)$ from four populations on the territory of Armenia were used for this study (Table 1). The lizards were caught in the period from 1997 to 2006 in their natural habitats. All field studies were carried out until D. rostombekowi species was included in the Red Book of Armenia as an "endangered" species according to IUCN criteria (Endangered, EN B1ab) (Agasyan et al., 2010). In this work, the analysis was carried out on the basis of three previously described microsatellite-containing loci Du215, Du281, and Du323 (Ryskov et al., 2017) and the new Du47G locus. These loci were established to study other parthenogenetic species of this genus: D. unisexualis (Badaeva et al., 2008) and D. dahli (Vergun et al., 2014).

A locus-specific polymerase chain reaction was performed using previously selected primer pairs and amplification conditions (Korchagin et al., 2007; Vergun et al., 2014).

The DNA extraction method and analysis of microsatellite-containing loci Du215, Du281, Du323, and Du47G are presented in the following works (Korchagin et al., 2007; Osipov et al., 2016; Ryskov et al., 2017). The sequences obtained as a result of sequencing were deposited in GenBank (KM573728-KM573762; HM014002-HM014003; KR559279KR559316; and MK622868-MK622872).

The analysis and comparison of the sequences obtained were carried out in the MEGA v.7.0.21 software. The number of alleles, allelic richness as a measure of the number of alleles (adjusted for the sample size), and expected heterozygosity as a measure of gene diversity were calculated for each locus and population using Fstat v.2.9.3.2., GenePop v.4.2, and the online version of POPTREEW. AMOVA analysis was performed using the Poppr package (Kamvar et al., 2014). Realization of multiple alignments of sequences of microsatellite alleles for three species was carried out using a MUSCLE algorithm (Edgar, R.C. et al., 2004). These matrices were used to construct a network by means of the nearest neighbor method using MEGA v.7.0.21 (Tamura et al., 2013). The composi- tion of genotypes was carried out by comparing and analyzing the combinations of allelic variants in the populations using the LabConverter V1 program (Omelchenko et al., 2016).

\section{Creating a Map of the Potential Range of Species}

Collecting field data. Data was collected by the authors during field studies in the period 1997-2019 and collection materials of the Department of Zoology of Yerevan State University (YSU), the Zoological Museum of Moscow University (ZMMU), the Museum of the Zoological Institute of Russian Academy of Sciences (ZISP), and the Canadian Royal Ontario Museum (ROM) were used. The potential habitats on routes with a total length of $3000 \mathrm{~km}$ in 2018 and $1800 \mathrm{~km}$ in 2019 were studied. Field surveys were carried out in the sunny windless hours in the morning. For each locality, the geographic coordinates and heights were determined using a Garmin Montana 680t GPS navigator (Garmin Corp., Olathe, KS, United States) with an error of $\pm 3.5 \mathrm{~m}$. The lizards from each location were captured and identified in the field conditions using a guide (Darevsky, 1967; Arakelyan et al., 2011).

Vector layers of the occurrence records. Field, museum, and literature data were used to create a vector database (VDB) in the ArcGIS Desktop 10.4.1 environment (Darevsky, 1967; Uzzell and Darevsky, 1975; MacCulloch et al., 1997; Martirosyan et al., 2002; Arakelyan et al., 2011; Ryskov et al., 2017).

Raster layers for constructing potential range maps. A review of the literature was conducted to select the most important variables determining the distribution of rock lizards (Darevsky, 1967; Uzzell and Darevsky, 1975; Kaliontzopoulou et al., 2008; Tarkhnishvili et al., 2010; Arakelyan et al., 2011; Doronin, 2015; Freitas et al., 2016, Petrosyan et al., 2019, 2020b). The selected environmental variables characterize the climate, topography, and land cover/land use. The spatial climatic variables were taken from a WorldClim 2.0 data set (http://worldclim.org/version2) with a resolution $30 \mathrm{~s}$ including 21 bioclimatic variables. In this work, the analysis was carried out for three different resolutions $(3,9$, and 30 arc second, that is, $\sim 90$, $\sim 270$, and $\sim 900 \mathrm{~m}$, respectively) of the raster relief layers, climatic parameters, and landscape. All these layers were prepared using the appropriate Arc GIS Desktop 10.4.1 software module using a cubic function of approximation. As a result of these transformations, all raster layers were presented with a resolution of $\sim 90, \sim 270$, and $\sim 900 \mathrm{~m}$, respectively.

To verify the spatial autocorrelation of the occurrence records from VDB, a two-step procedure described in the works (ESRI, 2017; Aiello-Lammens et al., 2015; Petrosyan et al., 2020b) was used.

The potential distribution model of $D$. rostombekowi was constructed by the maximum entropy method using MaxEnt 3.4.1 (Phillips et al., 2006) from the EcoSpat environment (De Pous et al., 2011; Di Cola 
et al., 2017). To construct the species distribution model (SDM), ten runs of MaxEnt with a random selection of test and training samples were used. In all variants of the MaxEnt run, $80 \%$ of find records were used as training samples, while $20 \%$ of records were used as test samples. We used the Boyce index $\left(\mathrm{B}_{\text {ind }}\right)$ to assess model performance using the EcoSpat package (Di Cola et al., 2017). The average Boyce index was determined by averaging the indices of ten models for each resolution separately. The importance of each predictor variable was determined using a table of contribution (AVC) MaxEnt (Phillips et al., 2006). Those variables that make a significant contribution to the model (that is, have high values of permutation importance (PI) or high values of the percentage of contribution (PC)) were considered as important variables (Phillips et al., 2006).

Similarity of ecological niches. A comparative analysis of the ecological niches of D. rostombekowi populations obtained for different data sets was carried out using a general concept presented in the following works (Petitpierre et al., 2012; Di Cola et al., 2017). The estimation of the niche overlap obtained based on different sets of occurrence records was conducted using Schoener's D index (Di Cola et al., 2017).

A comparative analysis of the centroids (average values of variables) of niches determining the spatial distribution of $D$. rostombekowi populations was carried out using the general linear model (GLM) procedure. In this model, the analysis of variance (ANOVA) was used. If ANOVA demonstrated a significant difference in the centroids, then it was determined using the Post hoc Tukey HSD multiple comparison methods precisely which centroids were different from each other.

Statistical analysis and construction of diagrams were performed in the RStudio 1.1.463 software.

\section{RESULTS}

\section{Genetic Characteristics of Populations}

The analysis of four microsatellite-containing loci Du215, Du281, Du323, and Du47G detected that all D. rostombekowi individuals studied are heterozygous for these loci. From two to five alleles (depending on the locus) were detected in the populations studied. The allelic variants of each locus are presented in Table 2.

Previously, structural differences of microsatellite loci Du215, Du281, and D323 were described (Osipov et al., 2016; Ryskov et al., 2017). The analysis of the Du47G locus allowed us to identify five allelic variants that differed in the structure of the microsatellite cluster, for which GATA and GACA repeats, as well as imperfect GAT elements, are typical. In addition, the allelic variants differed in fixed positions of the flanking regions, by which they can be divided into two groups: (1) A (+7), A (+21), G (+52) T (+58) typical for the Du47G(rost) 1 and Du47G(rost) 5 alleles; (2) T
$(+7), \quad \mathrm{T}(+21), \quad \mathrm{C}(+52) \quad \mathrm{T}(+58)$ typical for Du47G(rost)2-Du47G(rost)4 alleles (Table 2).

The number of genotypes was established by the analysis of the combination of allelic variants of each individual (Table 3, Fig. 1). The analysis of allelic combinations for the four loci detected seven genotypes unevenly distributed in the studied populations. Individuals with identical genotypes formed clonal lines. The major clone (genotype 1) was established in 24 individuals (57\% of all individuals studied) and presented in three populations, including Gosh, Papanino (vicinity of Dilijan town), and Spitak. The clones with the genotype 2 were found in seven individuals (17\%). The clones with the genotypes 3 (five individuals, 12\%) and 4 (three individuals, 7\%) were found only in the isolated Sevan population of Tsovak. Other genotypes $(5,6$, and 7$)$ were represented by only one individual and were found in the populations Gosh, Papanino, and Spitak.

Genotypes 1-7 differ from each other in the microsatellite cluster sequence. Rare genotypes found in single individuals in the populations are probably mutational derivatives of the main (represented by a large number of individuals and widespread in three out of four populations studied) genotype. The genotypes 3 and 4 are present only in the isolated population of Tsovak and are the «most distant» from the main genotype. The analysis of spatial-frequency distributions of most widespread genotypes 1 and 2 and population-specific genotypes 3 and 4 identified the dependence between the frequencies of clones and the geographical distribution between three northern populations and the Sevan population of Tsovak.

Taking genotype $1(\mathrm{G} 1)$ as the initial, according to Parker's model (Parker et al., 1989), we can assume that the remaining genotypes detected could have formed as a result of microsatellite mutations of the already formed initial clone. This event is reflected in the scheme (Fig. 2), which was constructed based on comparative analysis of the combinations of allelic variants for each locus taking into account the genotype distribution and its frequency in populations. As is seen from the scheme, the genotypes G2, G7 differ from the genotype G1 by a single GATA mutation in the microsatellite cluster by one out of four loci $(\mathrm{G} 1$ differs from G7 by a single mutation in the Du215 locus; G1 from G2, by a single mutation in the Du281 locus). The same pattern is observed between the genotypes G2 and G5. Although the genotype G6 is presented in the population Gosh, it is similar to the genotype G2 (present in the populations Spitak and Papanino), except for deletion of one GCAA element in the Du215 locus. Despite the fact that no genotypes G3 and G4 were found in other populations (except for Tsovak), they are associated with the main G1 genotype by common allelic variants; however, they are "distant" from it by multiple changes within the microsatellite cluster.

Data on the calculations of the genetic diversity indices in the populations of parthenogenetic species 
OSIPOV et al.

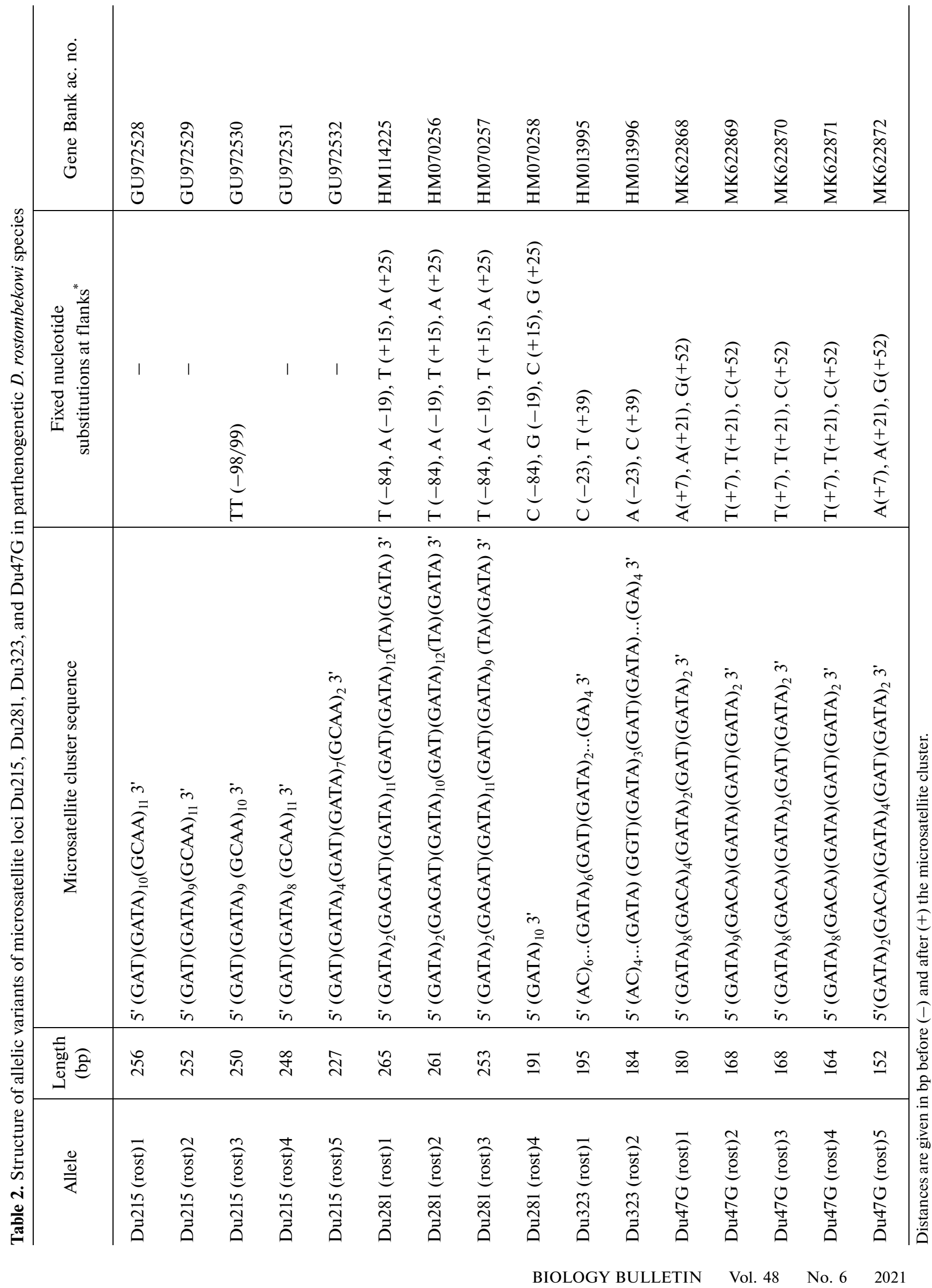


Table 3. Genotype diversity in D. rostombekowi populations by four microsatellite loci

\begin{tabular}{|c|c|c|c|c|c|c|}
\hline \multirow[b]{2}{*}{ Genotype } & \multirow[b]{2}{*}{ Combination of allelic variants } & \multicolumn{4}{|c|}{ Populations } & \multirow{2}{*}{$\begin{array}{l}\text { Number } \\
\text { of individuals } \\
\text { with a given } \\
\text { genotype }\end{array}$} \\
\hline & & 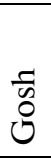 & 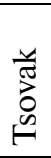 & 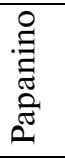 & 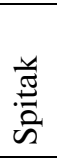 & \\
\hline 1 & $\mathrm{Du} 215(2+5)+\operatorname{Du} 281(1+4)+\operatorname{Du} 323(1+2)+\operatorname{Du} 47 \mathrm{G}(4+5)$ & 2 & 0 & 14 & 8 & 24 \\
\hline 2 & $\operatorname{Du} 215(2+5)+\operatorname{Du} 281(2+4)+\operatorname{Du} 323(1+2)+\operatorname{Du} 47 \mathrm{G}(4+5)$ & 0 & 0 & 6 & 1 & 7 \\
\hline 3 & $\operatorname{Du} 215(4+5)+\operatorname{Du} 281(3+4)+\operatorname{Du} 323(1+2)+\operatorname{Du} 47 \mathrm{G}(2+1)$ & 0 & 5 & 0 & 0 & 5 \\
\hline 4 & $\operatorname{Du} 215(4+5)+\operatorname{Du} 281(3+4)+\operatorname{Du} 323(1+2)+\operatorname{Du} 47 G(4+5)$ & 0 & 3 & 0 & 0 & 3 \\
\hline 5 & $\operatorname{Du} 215(2+5)+\operatorname{Du} 281(2+4)+\operatorname{Du} 323(1+2)+\operatorname{Du} 47 \mathrm{G}(3+5)$ & 0 & 0 & 1 & 0 & 1 \\
\hline 6 & $\operatorname{Du} 215(3+5)+\operatorname{Du} 281(2+4)+\operatorname{Du} 323(1+2)+\operatorname{Du} 47 \mathrm{G}(4+5)$ & 1 & 0 & 0 & 0 & 1 \\
\hline 7 & $\operatorname{Du} 215(1+5)+\operatorname{Du} 281(1+4)+\operatorname{Du} 323(1+2)+\operatorname{Du} 47 \mathrm{G}(4+5)$ & 1 & 0 & 0 & 0 & 1 \\
\hline \multicolumn{2}{|c|}{ Total number of individuals } & 4 & 8 & 21 & 9 & 42 \\
\hline \multicolumn{2}{|c|}{ Genotypic diversity } & 3 & 2 & 3 & 2 & \\
\hline
\end{tabular}

by four microsatellite loci are given in Table 4 . The level of expected heterozygosity $\left(H_{\mathrm{E}}\right)$ varies from 0.533 to 0.783 (on average, 0.581 ), while the number of alleles $(N)$ varies from two to four. The degree of allelic richness $\left(R_{\mathrm{s}}\right)$ varies from 1.995 to 4.000 (on average, 2.685). The highest index of this value was established in the Gosh populations for the Du215, Du281, and Du323 loci.

\section{Most Important Predictor Environmental Variables and the Potential Range of Parthenogenetic Species}

We collected 118 records with geographical coordinates of $D$. rostombekowi occurrence data in Armenia and Azerbaijan (49 published accounts and 69 of our own field records). After removing cluster points, there are 56 records left included in the reduced set for further analysis. Subsequently, these records (full $n=118$, reduced $n=56$ ) were used to construct species distribution models and to compare ecological niches for three resolutions $\sim 90, \sim 270$, and $\sim 900 \mathrm{~m}$, respectively.

We obtained "high" values of the Boyce index $\left(\mathrm{B}_{\text {ind }} \pm \mathrm{SD}\right)$ and AUC $( \pm \mathrm{SD})$ for all species distribution models. The contributions of variables for different SDM are presented in Table 5. It follows from Table 5 that the AUC index (Phillips et al., 2006) has sufficiently high values and varies from $0.978( \pm 0.007)$ to $0.985( \pm 0.007)$, which are slightly different from each other. The latter means that, regardless of the type of data use (reduced, full) and the spatial resolution of the layers, the AUC index of model suitability changes slightly (Table 5). Unlike the AUC, the Boyce index is sensitive and allows us to select the best model. In our case, the highest accuracy of the species distribution model is observed only for a single case, that is, when full data with the spatial resolution $\sim 90 \mathrm{~m}$ are used. In this case, the Boyce index is $0.958 \pm$ 0.004. The worst model according to the Boyce index $0.813( \pm 0.02)$ was constructed when using reduced data with the spatial resolution of $\sim 270 \mathrm{~m}$. The maps of the species distribution for these cases are presented in Fig. 3.

Table 4. Indices of genetic diversity in D. rostombekowi populations by four microsatellite loci

\begin{tabular}{|c|c|c|c|c|}
\hline Locus & Population & $N$ & $R_{\mathrm{s}}$ & $H_{\mathrm{E}}$ \\
\hline \multirow[t]{5}{*}{ Du215 } & Gosh & 4 & 4.000 & 0.750 \\
\hline & Tsovak & 2 & 2.000 & 0.533 \\
\hline & Papanino & 2 & 1.997 & 0.512 \\
\hline & Spitak & 2 & 2.000 & 0.529 \\
\hline & $\Sigma$ & 5 & 2.738 & 0.581 \\
\hline \multirow[t]{5}{*}{ Du281 } & Gosh & 3 & 3.000 & 0.679 \\
\hline & Tsovak & 2 & 2.000 & 0.533 \\
\hline & Papanino & 3 & 2.773 & 0.626 \\
\hline & Spitak & 3 & 2.443 & 0.582 \\
\hline & $\Sigma$ & 4 & 3.127 & 0.605 \\
\hline \multirow[t]{5}{*}{ Du323 } & Gosh & 2 & 2.000 & 0.571 \\
\hline & Tsovak & 2 & 2.000 & 0.533 \\
\hline & Papanino & 2 & 1.997 & 0.512 \\
\hline & Spitak & 2 & 2.000 & 0.529 \\
\hline & $\Sigma$ & 2 & 1.995 & 0.536 \\
\hline \multirow[t]{5}{*}{ Du47G } & Gosh & 2 & 2.000 & 0.571 \\
\hline & Tsovak & 4 & 3.774 & 0.783 \\
\hline & Papanino & 3 & 2.186 & 0.535 \\
\hline & Spitak & 2 & 2.000 & 0.529 \\
\hline & $\sum$ & 5 & 2.883 & 0.604 \\
\hline All loci & & 16 & 2.685 & 0.581 \\
\hline
\end{tabular}

$N$, number of alleles; $R_{\mathrm{s}}$, level of allelic richness; $H_{\mathrm{E}}$, value of expected heterozygosity. 


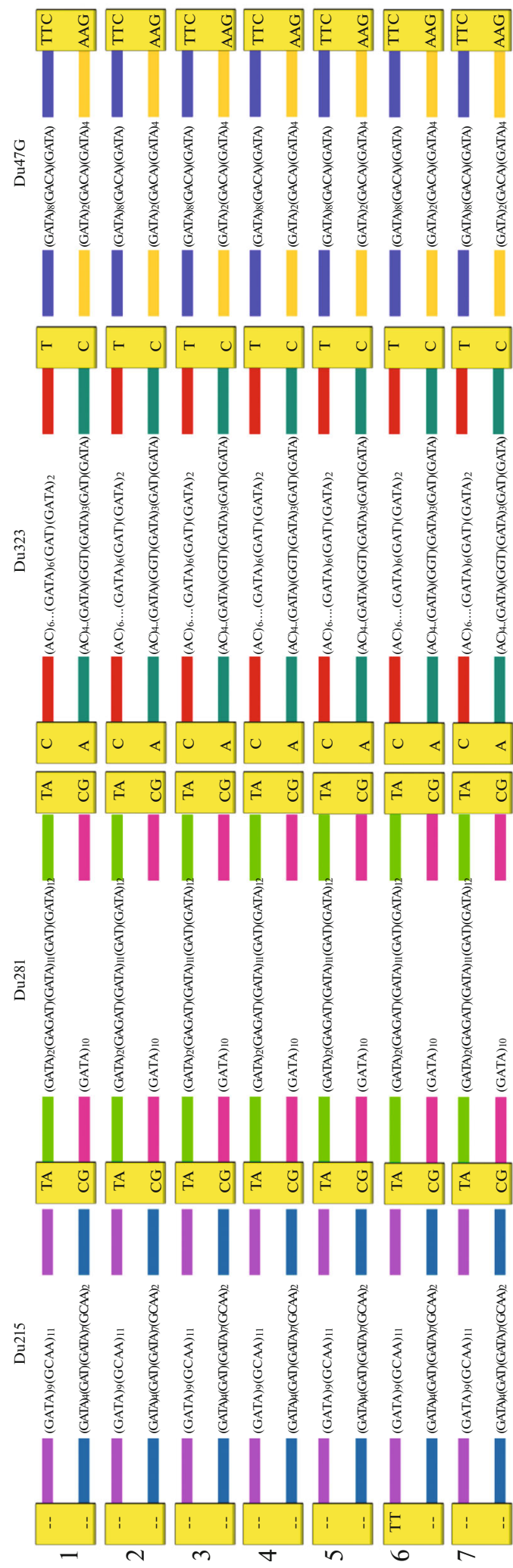

Fig. 1. Schematic representation of seven genotypes formed by allelic combination of microsatellite loci Du215, Du281, Du323, and Du47G in 42 D. rostombekowi individuals. SNV markers specific for parental species are demonstrated in squares. Variable microsatellite clusters are demonstrated for each allele.
It follows from Table 5 that only five out of eight predictor variables (MeanTempDrQ, Sradmean, PrecipCoefVar, IsoTerm, PrecWarmQ) are common for all 60 models (ten replications $\times$ two types of data sets $\times$ three resolutions). The importance of the StdDivTemp variable is highlighted for almost all models except for the models obtained for reduced data for the resolution of $\sim 90 \mathrm{~m}$. The importance of the HighWay variable is highlighted for all models with different resolutions when using the full set of find point data, as well as for the models with the resolution of $\sim 90 \mathrm{~m}$ when using the reduced data. Elevation is the only variable that is highlighted only for a single combination of the data set (full) and resolution $(\sim 90 \mathrm{~m})$.

A visual qualitative analysis of the best (Fig. 3a) and the worst (Fig. 3b) maps demonstrates that they coincide in general terms along the boundaries of the range, but there is a great difference in the details. The best map (Fig. 3a) indicates that the most suitable habitats (with a probability $>0.6$ ) are mainly located in northern Armenia, including all known habitats of the populations (Sevan, Spitak, Gosh, Dilijan, IjevanNoyemberyan), as well as new habitats of the western part of Lake Sevan and in the eastern part of Nagorno-Karabakh, the northern part of Armenia on the border with Georgia. The worst map demonstrates extensive suitable habitats on the western part of Lake Sevan, a vast area in the eastern part of NagornoKarabakh, in northern Armenia at the border with Georgia, and plots in the southern part of Georgia.

\section{Similarity Indices of Ecological Niches of Populations of Parthenogenetic Species}

The results of the analysis of niche overlapping for different data sets are presented in Fig. 4. It was demonstrated that the similarity index of ecological niches for different resolutions changes in the range from 86 to $90 \%$ depending on the resolution of the layers used. The portion of common habitats (that is, niche overlapping) varies from 97.8 to $98.8 \%$. The similarity test of ecological niches obtained based on different data sets does not deviate for all resolutions $(P<0.02)$.

Despite the great similarity of ecological niches when using different data sets, however, the centroid is shifted upward in height for reduced data (Figs. 4d-4f). This means that thinning in order to remove the clustered points leads to a significant decrease in the number of points in the habitats of northern populations (Spitak, Gosh, Papanino, and Ijevan-Noyemberyan) and leaves unchanged the number of find points in the southern part of Lake Sevan (Tsovak). Eventually, this leads to an increase in the centroid height and an increase in the habitat suitability at an altitude of more than $2000 \mathrm{~m}$.

\section{Comparative Analysis of Centroids of Niches of Parthenogenetic Species Populations}




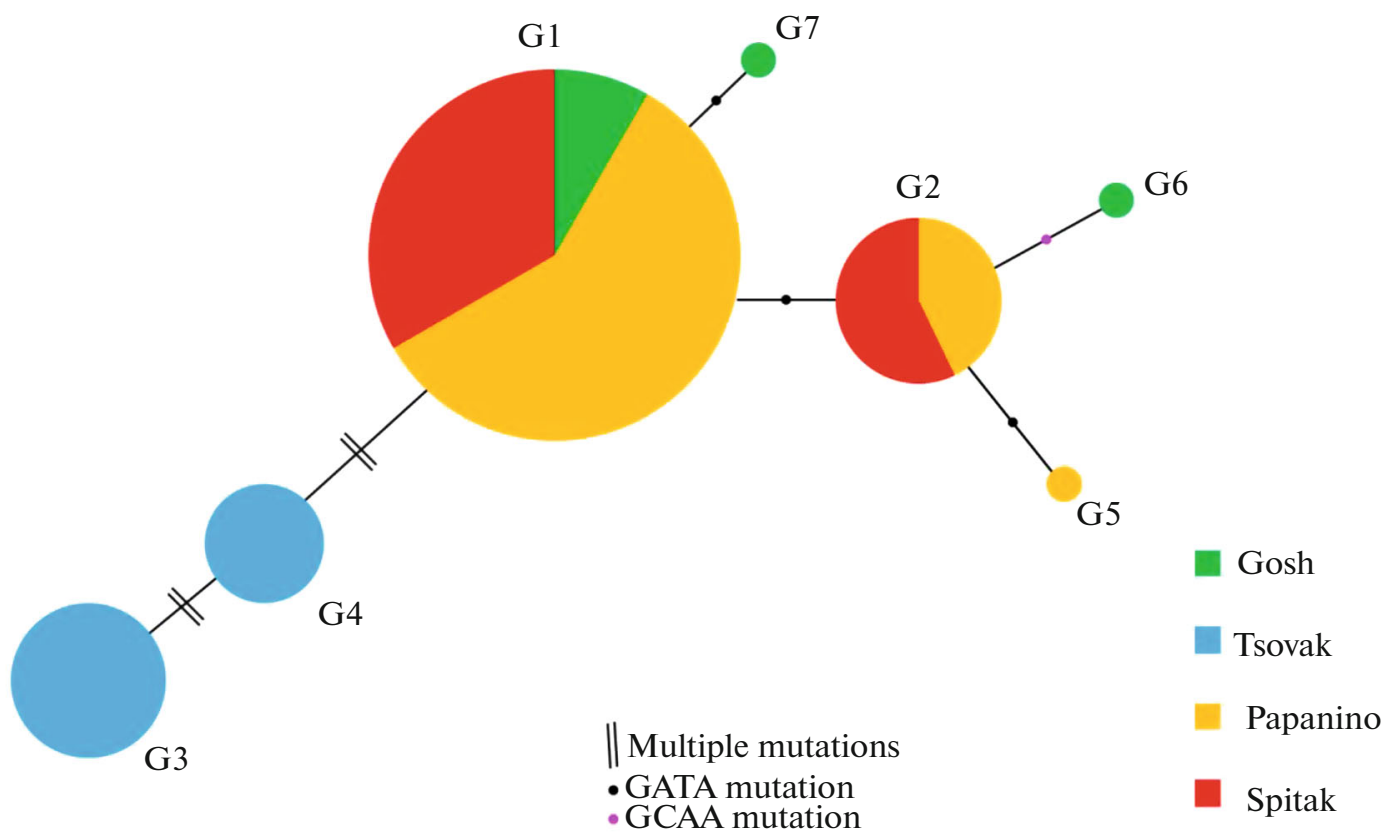

Fig. 2. Schematic representation reflecting the relationship between the genotypes $1-7(\mathrm{G} 1-\mathrm{G} 7)$ in the $D$. rostombekowi populations studied.

(a)

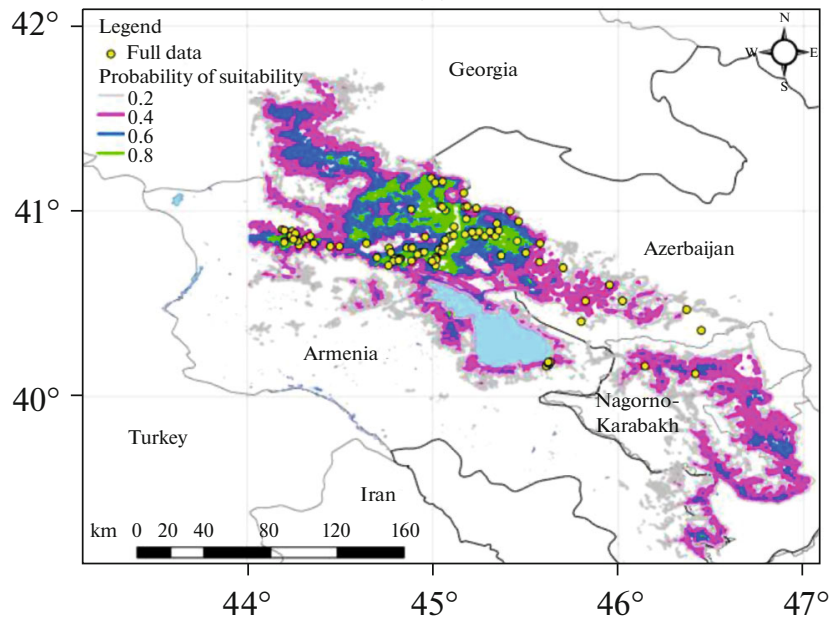

(b)

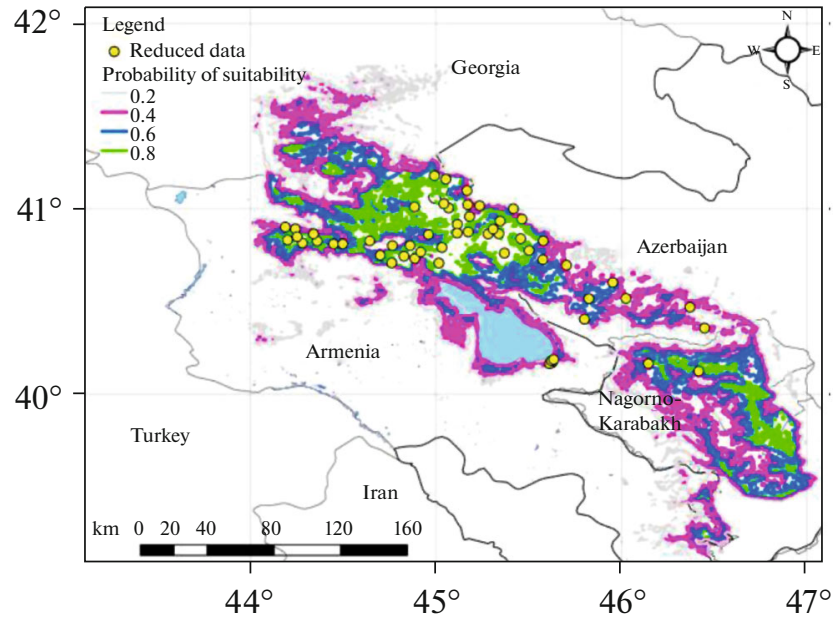

Fig. 3. Maps of D. rostombekowi distribution using different data sets and resolutions. (a) Full set of find points and spatial resolution of $90 \mathrm{~m}$; (b) reduced set of data and spatial resolution of $270 \mathrm{~m}$.

To check the statistical significance of the difference of niche centroids by abiotic environmental factors of different populations, we carried out their comparative analysis. The results of comparison of the mean values of predictor variables (niche centroids) of united northern populations and the isolated Tsovak population are presented in Fig. 5. It follows from Fig. 5 that the ecological conditions of the Tsovak population are statistically significantly different from northern populations in the average temperature and total precipitation of the dry quarter of the year, the average solar radiation, precipitation coefficient of variation, isothermality, and elevation. The southern population differs from the northern populations not only by the distance to the roads, but also by standard deviation of temperature.

\section{DISCUSSION}

A comparative analysis of single nucleotide variants outside the microsatellite cluster (SNV) of D. rostombekowi parthenogenetic species with parental spe- 

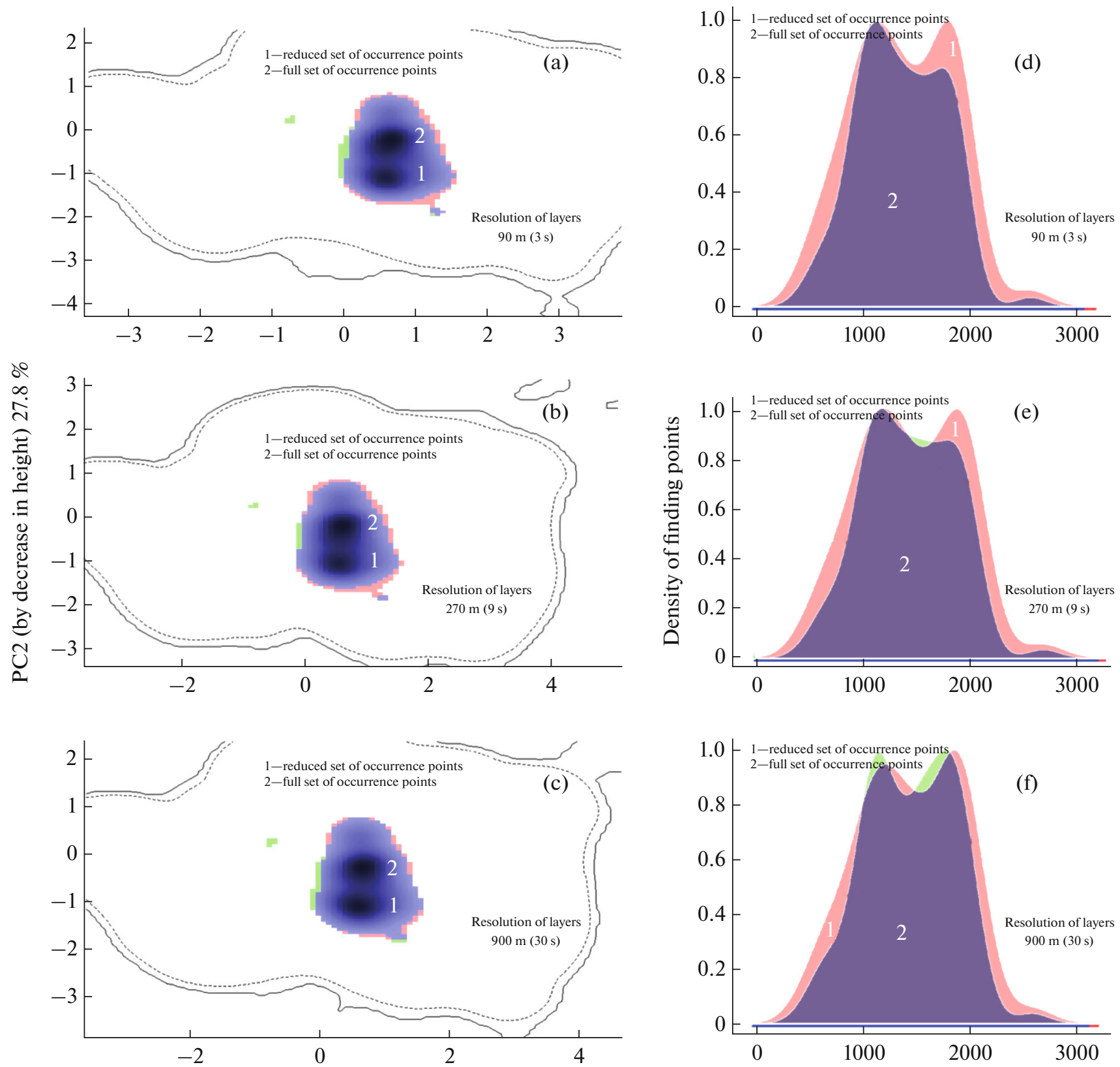

PC1 (amount of precipitation in the warmest quarter of the year) $56.2 \%$

Elevation

Fig. 4. Ecological niches of D. rostombekowi (a), (b), (c) presented using two axes of principal components and shifts of niche centroids (d), (e), (f) by height obtained based on reduced find points of relatively full ones. Shaded areas demonstrate realized niches for different sets of points and resolutions; dotted and solid lines in the figures (a), (b), (c), for $90,100 \%$ of the area of the study region.

cies (D. r. raddei, D. portschinskii) (Osipov et al., 2016; Ryskov et al., 2017) suggests that the parthenogenetic species could be formed as a result of a single hybridization event between close related bisexual individuals of the parental species, since the studied individuals of the parthenogenetic species did not differ by SNV in all four microsatellite loci (Fig. 1).

The analysis of distributions of the most widespread genotypes 1 and 2 and population-specific genotypes 3 and 4 revealed a dependence between the fre- quencies of clones and geographical separation between three northern populations and Sevan population Tsovak. The question remains which of the seven $D$. rostombekowi clones established was formed first. Assuming that the parthenogenetic species formed as a result of a single hybridization event has a spread and most common "major" clone with several "minor" clones (Parker et al., 1989), the genotype G1 could probably be the initial one. The remaining genotypes are G1 mutations. Mutations de novo in all four loci studied are caused by deletion or insertion of a 

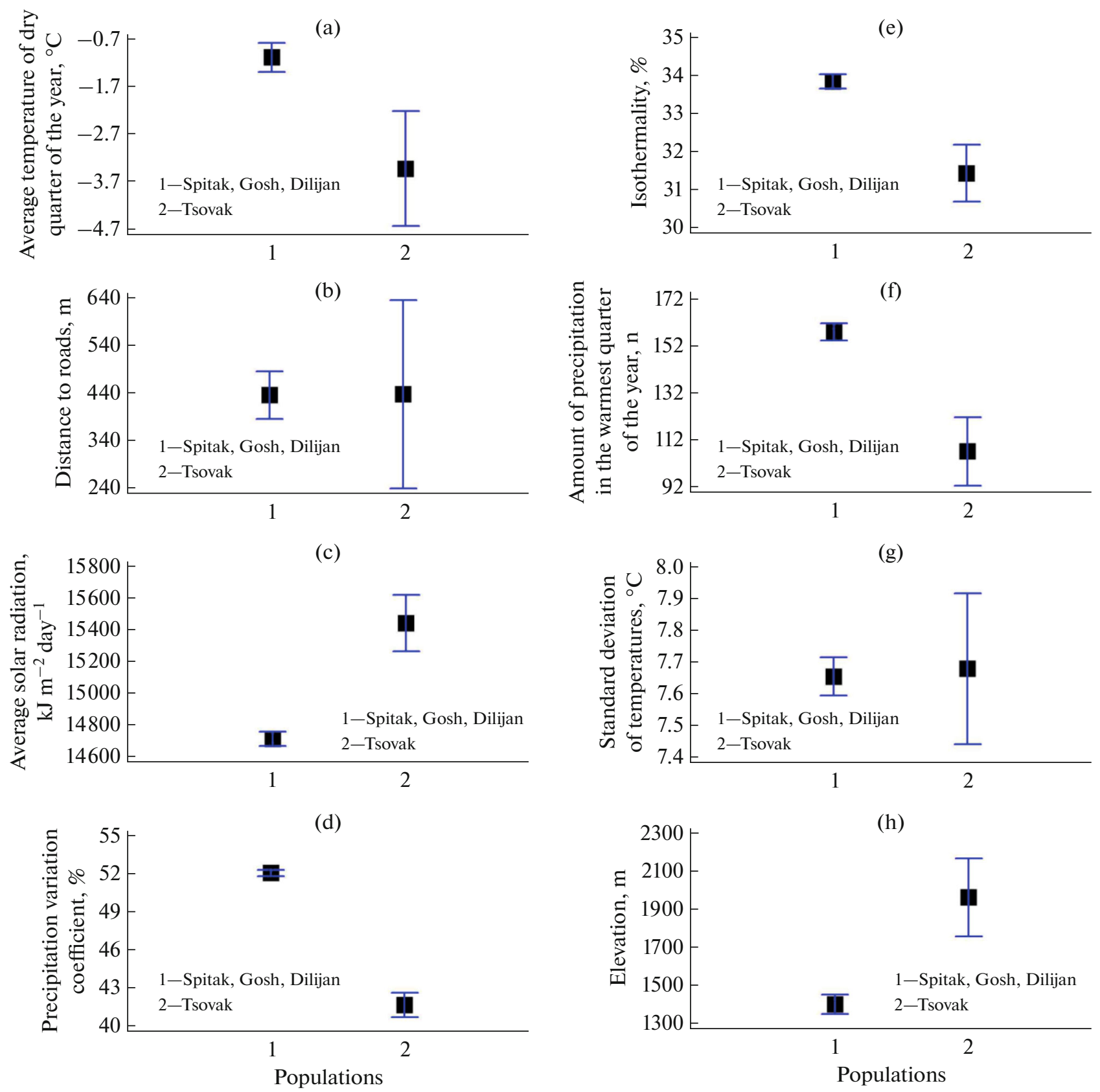

Fig. 5. Comparison of average values of predictor variables (centroids) of northern populations and isolated Tsovak population. Average values with 95\% Tukey confidence intervals using ANOVA GLM are presented in the graph: (a) $F=6.9 ; P=0.01$; (b) $F=$ $0.001 ; P=0.99$; (c) $F=30.95, P \ll 0.001$; (d) $F=212.8, P \ll 0.001$; (e) $F=18.98, P \ll 0.001$; (f) $F=22.36, P \ll 0.001$; (g) $F=$ $0.02, P=0.89$; (h) $F=13.9, P=0.0003$.

microsatellite repeat (Fig. 1, Table 2). Noticeable differences of the genotypes G3 and G4 from the main genotype G1 and genotypes G2, G5, G6, G7 (found in the populations Gosh, Papanino, and Spitak) can be associated with significant differences in the ecological conditions of their habitats (Fig. 5). Most likely, other (transitional clonal lines) between genotypes $1-3$ and 4 could have been lost as a result of reduction and/or rupture of the range of $D$. rostombekowi.
In this work, it was demonstrated that SDM is an important instrument, which can be used to detect ecological requirements of $D$. rostombekowi populations to the environment and to select the most important variables determining their spatial distribution. The additional analysis using an ordination method allows us to conduct a comparative analysis of ecological niches of different populations and to determine the measure of their overlap and similarity and to detect significant shifts of niches in identifying 
potential ranges on the basis of different sets of occurrence records and resolutions of the layers of predictor variables. These two approaches, as well as the genetic structure of the populations, allow us to reveal their peculiarities and to estimate the role of ecological factors in the formation of the northern and southern populations of this species.

\section{Most Important Variables Determining the Distribution Model of Parthenogenetic Species}

As demonstrated by SDM, the average temperature and total precipitation in the dry and warm quarters of the year, the solar radiation, precipitation coefficient of variation, isothermality, and elevation are important environmental factors that affect the formation of the spatial distribution of lizards on the territory of Armenia, Nagorno-Karabakh, and Azerbaijan (Fig. 3, Table 5). It follows from this that the set of variables determining suitable habitats is largely associated with the thermal conditions and humidity in the dry and warm seasons, respectively, as well as with the annual coefficients of variation of these variables. Moreover, isothermality should be within $28-34 \%$, while the precipitation humidity coefficient is $41-52 \%$ (Fig. 4). It is important to note that the isothermality, which reflects sufficiently high temperature stability and its low fluctuations in habitats, has not previously been noted for other lizard species as the most important predictor variable (Kaliontzopoulou et al., 2008; De Pous et al., 2011). The narrow range of variation of these variables means a sufficiently high sensitivity of the species to climate change. The established vari- ables explain the ecological peculiarities associated with the distribution of D. rostombekowi and give an idea of the factors limiting its spread. Solar radiation is another important variable, which provides warming up of the soil in habitats and changes in the narrow range of 4.1$4.2 \mathrm{~kW} * \mathrm{~h} / \mathrm{m}^{2}$. The elevation is the important variable only for one (the best) model, which was obtained

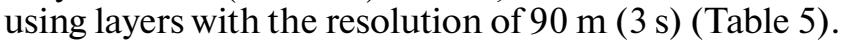

\section{Potential Range of Parthenogenetic Species}

The occurrence records and potential range of D. rostombekowi demonstrate that the species is distributed quite widely in the northeastern part of Armenia, in the northwestern part of Azerbaijan, and on the territory of Nagorno-Karabakh (Fig. 3a). Most places where $D$. rostombekowi was previously observed are easily predictable using SDM (Darevsky, 1967; Uzzell, 1975; Martirosyan et al., 2003; Arakelyan et al., 2011). Actually, the model of the potential range of $D$. rostombekowi predicted a wider range of distribution outside of the already known suitable habitats of the populations Spitak, Gosh, Papanino, Ijevan, Noyemberyan, and Tavush, as well as the southern population on the coast of Lake Sevan, where the species was already registered. In addition, the model highlights new small suitable habitats of the western part of Lake Sevan and the eastern part of Nagorno-Karabakh, and the northern part of Armenia on the border with Georgia. In general, the low demand of the species for vegetation according to the results of MaxEnt modelling is reflected in the potential distribution model,

Table 5. Sets of predictor variables determining the models of $D$. rostombekowi distribution with indication of the indices of suitability (AUC and Boyce) for maps of potential ranges obtained using MaxEnt and EcoSpat. Only variables that contributed more than $5 \%$ either by PC or by PI are presented

\begin{tabular}{|c|c|c|c|c|c|c|c|c|c|c|c|c|}
\hline \multirow{4}{*}{ Variable* } & \multicolumn{6}{|c|}{ Full set of find points } & \multicolumn{6}{|c|}{ Reduced set of find points } \\
\hline & \multicolumn{12}{|c|}{ Resolution } \\
\hline & \multicolumn{2}{|c|}{$90 \mathrm{~m}$} & \multicolumn{2}{|c|}{$270 \mathrm{~m}$} & \multicolumn{2}{|c|}{$900 \mathrm{~m}$} & \multicolumn{2}{|c|}{$90 \mathrm{~m}$} & \multicolumn{2}{|c|}{$270 \mathrm{~m}$} & \multicolumn{2}{|c|}{$900 \mathrm{~m}$} \\
\hline & $\mathrm{PC}$ & PI & $\mathrm{PC}$ & PI & PC & PI & $\mathrm{PC}$ & PI & $\mathrm{PC}$ & PI & $\mathrm{PC}$ & PI \\
\hline MeanTempDrQ & 20.1 & 31.5 & 19.6 & 35.4 & 20.3 & 31.6 & 29 & 66.8 & 30 & 63.7 & 27.6 & 60 \\
\hline HighWay & 17.6 & 1.2 & 12.9 & 0.5 & 9.7 & 1.4 & 6.2 & 0.9 & 4.6 & 0 & 4.6 & 0.1 \\
\hline Sradmean & 15.7 & 17.9 & 1.2 & 6.4 & 4.3 & 9.4 & 16.2 & 5.5 & 0.7 & 6.1 & 3 & 6.8 \\
\hline PrecipCoefVar & 11.2 & 17.3 & 19.3 & 21.7 & 21.2 & 23.4 & 19.6 & 13.5 & 21.4 & 12.1 & 22.3 & 16.8 \\
\hline IsoTerm & 9.8 & 3.3 & 19.3 & 9 & 21.7 & 16.1 & 8.2 & 4.8 & 18.2 & 3.5 & 18.6 & 5.8 \\
\hline PrecWarmQ & 7.9 & 3.5 & 15.8 & 6.2 & 14.3 & 7.7 & 9.8 & 2.6 & 14.3 & 3.4 & 15.2 & 3.5 \\
\hline StdDivTemp & 4.2 & 18.3 & 3.7 & 18.6 & 1.7 & 5.0 & 4.9 & 4.9 & 5.2 & 9.5 & 4.2 & 5.8 \\
\hline Elevation & 4.7 & 5.7 & 1.5 & 1.6 & 1 & 0.8 & 0.2 & 1 & 0.2 & 1 & 0.4 & 0.4 \\
\hline AUC index & \multicolumn{2}{|c|}{$0.979 \pm 0.011$} & \multicolumn{2}{|c|}{$0.98 \pm 0.01$} & \multicolumn{2}{|c|}{$0.978 \pm 0.007$} & \multicolumn{2}{|c|}{$0.979 \pm 0.009$} & \multicolumn{2}{|c|}{$0.982 \pm 0.007$} & \multicolumn{2}{|c|}{$0.985 \pm 0.007$} \\
\hline Boyce index & \multicolumn{2}{|c|}{$0.958 \pm 0.004$} & \multicolumn{2}{|c|}{$0.926 \pm 0.006$} & \multicolumn{2}{|c|}{$0.916 \pm 0.003$} & \multicolumn{2}{|c|}{$0.814 \pm 0.009$} & \multicolumn{2}{|c|}{$0.813 \pm 0.02$} & \multicolumn{2}{|c|}{$0.939 \pm 0.003$} \\
\hline
\end{tabular}

* MeanTempDrQ, average temperature of the dry quarter of the year $\left({ }^{\circ} \mathrm{C}\right)$; HighWay, distance to roads $(\mathrm{m})$; Sradmean, average solar radiation $\left(\mathrm{Kj} \mathrm{m}^{-2} \mathrm{day}^{-1}\right)$; PrecipCoefVar, precipitation coefficient of variation (\%); IsoTerm, isothermality (\%); PrecWarmQ, amount of precipitation in the warmest quarter of the year $(\mathrm{mm})$; StdDivTemp, standard deviation of temperatures $\left({ }^{\circ} \mathrm{C}\right)$; Elevation, height above sea level $(\mathrm{m})$. 
which includes regions that are located in the forest zone $(64 \%)$, mountain meadows (12\%), mountain steppes (14\%), and anthropogenically transformed habitats (9\%) at the heights typical for mountain forests $(1394 \pm 37 \mathrm{~m})$ and mountain meadows and steppes $(1957 \pm 146 \mathrm{~m})$. Northern populations are mainly located in the forest zones; the isolated Sevan population is found in mountain meadows and steppes.

\section{CONCLUSION}

This study systematized knowledge about genetic variability and the distribution of parthenogenetic D. rostombekowi species in the native part of the range using four microsatellite-containing loci Du215, Du281, Du323, and Du47G and 118 records with the geographical coordinates of the species presence from the territory of Armenia, Azerbaijan, and NagornoKarabakh covering most of its range. During this study, we supplemented the available literature data with our own field observations and constructed the potential range of the species (PRS) based on the analysis of climatic, topographic, and landscape environment variables. The results of the genetic structure (GS) of the populations demonstrated that, despite the presence of seven clonal lines, the parthenogenetic species is characterized by a single monophyletic form; that is, it is formed as a result of a single hybridization event between close bisexual individuals of parental species. The analysis of PRS and GS indicated the difference of an isolated population of the southeastern part of Lake Sevan and northern populations in Armenia. These differences are expressed both in the shift of ecological niches of these populations relative to each other and in the difference of the established genotypes. The currently predicted distribution of $D$. rostombekowi using PRS identified new small habitats in the western part of Lake Sevan and the eastern part of Nagorno-Karabakh, and the northern part of Armenia on the border with Georgia, where the presence of the species has not previously been reported in the literature. The results of this study and the absence of polyphyletic forms can indicate its regression. The results are valuable to support future studies and can be used to guide environmental organizations in order to preserve the most important habitats of the species studied.

\section{ACKNOWLEDGMENTS}

The authors are grateful to the international organization ERSI for providing a free license for the use of ArcGIS Desktop 10.4.1 through a Conservation Grant (Esri Sales Order number 3128913; Esri Delivery number, 81833751; Sold-To/End-user customer number, 535452).

\section{FUNDING}

The collection, analysis, and preparation of materials for this article were supported by the Russian Foundation for Basic Research (project nos. 18-34-00361 and 17-0000427). Molecular genetic studies were supported by the Russian Science Foundation (project no. 19-14-00083).

\section{COMPLIANCE WITH ETHICAL STANDARDS Conflict of Interest}

The authors declare that they have no conflict of interest.

\section{Statement on the Welfare of Animals}

All applicable international, national, and/or institutional guidelines for the care and use of animals were followed.

\section{OPEN ACCESS}

This article is licensed under a Creative Commons Attribution 4.0 International License, which permits use, sharing, adaptation, distribution and reproduction in any medium or format, as long as you give appropriate credit to the original author(s) and the source, provide a link to the Creative Commons licence, and indicate if changes were made. The images or other third party material in this article are included in the article's Creative Commons licence, unless indicated otherwise in a credit line to the material. If material is not included in the article's Creative Commons licence and your intended use is not permitted by statutory regulation or exceeds the permitted use, you will need to obtain permission directly from the copyright holder. To view a copy of this licence, visit http://creativecommons.org/licenses/by/4.0/.

\section{REFERENCES}

Agasyan A. L., Kalashyan M.Yu. (eds.). The Red Book of Animals of the Republic of Armenia. Yerevan. Zangak publ. 2010. 368 p Aiello-Lammens, M.E., Boria, R.A., Radosavljevic, A., Vilela, B., and Anderson, R.P., SpThin: an R package for spatial thinning of species occurrence records for use in ecological niche models, Ecography, 2015, no. 38, pp. 541-545.

Arakelyan, M.S., Danielyan, F.D., Corti, C., Sindaco, R., and Leviton, A.E., Herpetofauna of Armenia and NagornoKarabakh, Salt Lake City: SSAR Publ., 2011.

Badaeva, T.N., Malysheva, D.N., Korchagin, V.I., and Ryskov, A.P., Genetic variation and de novo mutations in the parthenogenetic Caucasian rock lizard Darevskia unisexualis, PLoS One, 2008, vol. 3, p. 2730. https://doi.org/10.1371/journal.pone.0002730PMID:18648496 Darevsky, I.S., Skal'nye yashcheritsy Kavkaza: sistematika, ekologiya, filogeniya polimorfnykh yashcherits podroda Arshaeolaserta (Rock Lizards of the Caucasus: Taxonomy, Ecology, Phylogeny of Polymorphic Lizards of the Subgenus Archeolacerta), Leningrad: Nauka, 1967.

De Pous, P., Mora, E., Metallinou, M., Escoriza, D., Comas, M., Donaire, D., Pleguezuelos, J.M., and Carranza, S., Elusive but widespread? The potential distribution and genetic variation of Hyalosaurus koellikeri (Gunther, 1873) in the Maghreb, Amphib. Reptiles, 2011, no. 32, pp. 385-397. 
Di Cola, V., Broennimann, O., Petitpierre, B., Breiner, F.T., D’Amen, M., Randin, C., Engler, R., Pottier, J., Pio, D., Dubuis, L., Pellissier, R.G., Mateo, W., Hordijk, N., Salamin, N., and Guisan, A., Ecospat: an R package to support spatial analyses and modeling of species niches and distributions, Ecography, 2017, vol. 40, pp. 1-14.

Doronin, I.V., Distribution data of rock lizards from the Darevskia (Praticola) complex (Sauria: Lacertidae), Curr. Stud. Herpetol., 2015, vol. 15, nos. 1/2, pp. 3-38.

Edgar, R.C., MUSCLE: multiple sequence alignment with high accuracy and high throughput, Nucleic Acids Res., 2004, vol. 32, pp. 1792-1797.

https://doi.org/10.1093/nar/gkh340PMID:15034147

ESRI (Environmental Systems Research Institute): Arc GIS Desktop 10.4.1-ESRI, Redlands, California, 2017.

Freitas, S., Rocha, S., Campos, J., Ahmadzadeh, F., Corti, C., Sillero, N., Ilgaz, C., Kumlutas, Y., Arakelyan, M., Harris, D.J., and Carretero, M.A., Parthenogenesis through the Ice Ages: a biogeographic analysis of Caucasian rock lizards (genus Darevskia), Mol. Phylogen. Evol., 2016, vol. 102, pp. 117-127.

Kaliontzopoulou, A., Brito, J., Carretero, M.A., Larbes, S., and Harris, D.J., Modelling the partially unknown distribution of wall lizards Podarcis in North Africa: ecological affinities. Potential areas of occurrence and methodological constraint, Can. J. Zool., 2008, vol. 86, pp. 992-1101.

Kamvar, Z.N., Tabima, J.F., and Gruenwald, N.J., Poppr: an R package for genetic analysis of populations with clonal, partially clonal, and/or sexual reproduction, Peer J., 2014, vol. 2 , p. 281.

https://doi.org/10.7717/peerj.281

Korchagin, V.I., Badaeva, T.N., Tokarskaya, O.N., Martirosyan, I.A., Darevsky, I.S., and Ryskov, A.P., Molecular characterization of allelic variants of (GATA)n microsatellite loci in parthenogenetic lizards Darevskia unisexualis (Lacertidae), Gene, 2007, vol. 292, pp. 126-133.

Malysheva D.N., Tokarskaya O.N., Martirosyan I.A., Ryskov A.P., Darevsky I.S., Petrosyan V.G. Analysis of genetic variation in unisexual and bisexual lizard species of the genus Leiolepis from Southeast Asia // Rus. J. Gen. 2006. T. 42. № 5. P. 463-467.

Martirosyan I.A., Ryskov A.P., Tokarskaya O.N., Petrosyan V.G., Arakelyan M.S., Aslanyan A.V., Danielyan F.D., Darevsky I.S. Variation of mini- and microsatellite DNA markers in populations of parthenogenetic rock lizard Darevskia rostombekowi // Rus. J. Genetics. 2002. T. 38. № 6. P. 691-698.

MacCulloch R. D., Murphy, R.W., Kupriyanova, L.A., and Darevsky, I.S., The Caucasian rock lizard Lacerta rostombekovi: a monoclonal parthenogenetic vertebrate, Biochem. Syst. Ecol., 1997, vol. 25, pp. 33-37.

Omelchenko, A.V., Vergun, A.A., Omel'chenko, E.V., and Lushnikova, A.A., Certificate of state registration of a computer program no. 2016610517 "Laboratory Converter No. 1-LabConverterV1," registration date January 13, 2016. https://patentinform.ru/programs/reg-2016610517.html. Checked August 26, 2019.

Osipov F.A., Vergun A.A., Girnyk A.E., Ryskov A.P., Kutuzova N.M. Molecular genetic characteristics of the allelic variants of microsatellite loci du281. du215. and du323 in parthenogenetic lizards Darevskia rostombekovi (fam.
Lacertidae)// Mol. Gen. Microbiol. Virology. 2016. V. 31. № 2. C. 69-74.]Parker, E.D., Walker, J.M., and Paulissen, M.A., Clonal diversity in Cnemidophorus: ecological and morphological consequences, in Evolution and Ecology of Unisexual Vertebrates, Dawley, R.M. and Bogart, J.P., Eds., New York State Mus. Bull. (Albany), 1989, 466, pp. 72-76.

Petitpierre, B., Kueffer, C., Broennimann, O., Randin, C., Daehler, C., and Guisan, A., Climatic niche shifts are rare among terrestrial plant invaders, Science, 2012, vol. 335, pp. $1344-1348$.

Petrosyan, V., Osipov, F., Bobrov, V., Dergunova, N., Nazarenko, E., Omelchenko, A., Danielyan, F., and Arakelyan, M., Analysis of geographical distribution of the parthenogenetic rock lizard Darevskia armeniaca and its parental species (D. mixta, D. valentini) based on ecological modeling, Salamandra, 2019, vol. 55, pp. 173-190.

Petrosyan, V.G., Osipov, F.A., Bobrov, V.V., Dergunova, N.N., Kropachev, I.I., Danielyan, F.D., and Arakelyan, M.S., New records and geographic distribution of the sympatric zones of unisexual and bisexual rock lizards of the genus Darevskia in Armenia and adjacent territories, Biodiversity Data J., 2020a, vol. 8, e56030.

https://doi.org/10.3897/BDJ.8.e56030

Petrosyan, V., Osipov, F., Bobrov, V., Dergunova, N., Omelchenko, A., Varshavskiy, A., Danielyan, F., and Arakelyan, M., Species distribution models and niche partitioning among unisexual Darevskia dahli and its parental bisexual (D. portschinskii, D. mixta) rock lizards in the Caucasus, Mathematics, 2020b, vol. 8, no. 8 .

https://doi.org/10.3390/math8081329

Phillips, S.J., Anderson, R.P., and Schapire, R.E., Maximum entropy modeling of species geographic distributions, Ecol. Model., 2006, vol. 190, pp. 231-259.

Ryskov, A.P., Osipov, F.A., Omelchenko, A.V., Semyenova, S.K., Girnyk, A.E., Korchagin, V.I., Vergun, A.A., and Murphy, R.W., The origin of multiple clones in the parthenogenetic lizard species Darevskia rostombekowi, PLoS One, 2017, vol. 12, no. 9.

https://doi.org/10.1371/journal.pone.0185161

Tamura, K., Stecher, G., Peterson, D., Filipski, A., and Kumar, S., MEGA6: molecular evolutionary genetics analysis version 6.0, Mol. Biol. Evol., 2013, vol. 30, pp. 27252729.

Tarkhnishvili, D., Gavashelishvili, A., Avaliani, A., Murtskhvaladze, M., and Mumladze, L., Unisexual rock lizard might be out competing its bisexual progenitors in the Caucasus, Biol. J. Linn. Soc., 2010, vol. 101, pp. 447-460.

Uzzell, T. and Darevsky, I.S., Biochemical evidence for the hybrid origin of the parthenogenetic species of Lacerta saxicola complex (Sauria, Lacertidae) with a discussion of some ecological and evolutionary implications, Copeia, 1975, vol. 2, pp. 204-222.

Vergun, A.A., Martirosyan, I.A., Semyenova, S.K., Omelchenko, A.V., Petrosyan, V.G., and Lazebny, O.E., Clonal diversity and clone formation in the parthenogenetic Caucasian rock lizard Darevskia dahli, PLoS One, 2014, vol. 9, no. 3. e91674.

https://doi.org/10.1371/journal.pone.0091674PMID:24618670

Translated by A. Barkhash 